\title{
Prevalence of quadriceps muscle weakness in patients with COPD and its association with disease severity
}

\author{
This article was published in the following Dove Press journal: \\ International Journal of COPD \\ I September 2015 \\ Number of times this article has been viewed
}

\author{
Sidharth Kharbanda' \\ Anand Ramakrishna ${ }^{2}$ \\ Shyam Krishnan ${ }^{3}$ \\ 'Kasturba Medical College, Manipal \\ University, ${ }^{2}$ Department of \\ Respiratory Medicine, ${ }^{3}$ Department \\ of Physiotherapy, Kasturba Medical \\ College Hospital, Mangaluru, \\ Karnataka, India
}

Introduction: COPD presents with an array of extra-pulmonary symptoms of which skeletal muscle dysfunction, particularly of the quadriceps, is well recognized. This contributes to impaired quality of life and increased health care utilization. Work on the quadriceps originated from the observation that a good proportion of COPD patients stop exercise due to the feeling of leg fatigue rather than breathlessness. This study was carried out with the aim of finding the prevalence of quadriceps weakness in a population set and correlate it with severity of COPD.

Methodology: This cross-sectional study was conducted in 75 subjects suffering from COPD aged 45 years or above. COPD severity in the subjects was graded based on the GOLD staging system. A digital hand held dynamometer (HHD) was used to measure quadriceps muscle strength. Descriptive statistics were done, and Pearson's Correlation Coefficient and ANOVA analysis was used for expressing the results.

Results: Ninety two percent of subjects were suffering from quadriceps muscle weakness. Quadriceps weakness was present in significantly high proportions even in those suffering from mild disease and belonging to a younger age group. The mean quadriceps muscle force value decreased with disease severity and this relation was found to be significant $(P<0.01)$.

Conclusion: Majority of the COPD patients were found to be suffering from quadriceps weakness, which was also present in significant proportions in subjects belonging to younger age groups and suffering from mild disease. These findings indicate that onset of muscle weakness in COPD may precede the onset of symptoms. These findings suggest need for early remedial measure to prevent occurrence of associated systemic diseases.

Keywords: COPD, GOLD staging, Quadriceps muscle strength, hand-held dynamometer, skeletal muscle dysfunction, spirometry, $\mathrm{FEV}_{1}, \mathrm{FVC}$

\section{Introduction}

Chronic obstructive pulmonary disease (COPD) affects various structural and functional domains in the lungs. It also has significant extrapulmonary effects, the so-called systemic effects of COPD. Nutritional abnormalities, weight loss, and skeletal muscle dysfunction are well-recognized systemic effects of COPD. Other less well-known but potentially important systemic effects include an increased risk of cardiovascular disease and severe neurological and skeletal defects. ${ }^{1}$ The skeletal muscles provide the mechanical basis for respiration and movement and their dysfunction significantly influences symptoms, functional capacity, increased utilization of health care facilities, quality of life, and even mortality. ${ }^{2-5}$ Skeletal muscle dysfunction, particularly of the quadriceps, is well recognized in COPD. Much work on the quadriceps originated
Correspondence: Sidharth Kharbanda Kasturba Medical College, Mangaluru, Manipal University, Light House Hill Road, Mangaluru, Karnataka 57500 I, India

Tel +919591306718

Emailsidk25@gmail.com 
from the observation that, despite the severe abnormalities in respiratory mechanics, a good proportion of patients with COPD stop exercise due to the subjective feeling of leg fatigue rather than breathlessness. ${ }^{6}$

The magnitude of quadriceps weakness has been related to disease severity in a previous study, ${ }^{7}$ but there is a wide variation for a given forced expiratory volume in 1 second $\left(\mathrm{FEV}_{1}\right)$. Many theories have been hypothesized for this. The theory of inactivity is favored by the preferential involvement of lower limb muscle (generally less active in COPD) over upper limb muscle, ${ }^{7,8}$ as well as sparing of the diaphragm, ${ }^{9}$ which shows increased activity. This argument is further supported by the observation that exercise training ${ }^{10}$ and possibly externally applied nerve stimulation ${ }^{11}$ can reverse disease-induced changes in the muscle. COPD patients have also been documented to adopt a more sedentary lifestyle due to major limiting symptoms such as breathlessness, and usually have a lower level of physical activity than the recommended international guidelines for maintenance of physical health. ${ }^{12}$ Physical activity and steps per day were found to be reduced among COPD patients, even in those with less severe disease, as demonstrated by Watz et al. ${ }^{13}$ This inactivity can often precipitate a "downward spiral of disease". Physical inactivity due to breathlessness leads to muscle deconditioning and a shift toward anaerobic metabolism. This leads to accumulation of lactate and carbon dioxide, which stimulates ventilation, hence worsening breathlessness. ${ }^{14}$ The loss in muscle mass observed in COPD patients with advancing airway obstruction and increased physical inactivity correlates with the reduced muscle force, ${ }^{15}$ thus supporting the etiological role of physical inactivity in the development of skeletal muscle dysfunction in such patients.

Another explanation is that muscle wasting is the result of a systemic inflammatory response. This hypothesis is supported by data showing that patients who fail to gain weight during a refeeding program have high levels of soluble tumor necrosis factor (TNF) receptor $55 .{ }^{16}$ In addition, skeletal muscle mass in COPD is inversely related to circulating levels of interleukin (IL)- 6 and TNF- $\alpha .{ }^{17}$ Against this background, Spruit et $\mathrm{al}^{18}$ presented data indicating that recurrent exacerbations result in stepwise impairment of muscle function. Increased levels of proinflammatory cytokines and acute phase proteins, which have been postulated either to originate from the respiratory muscles or the peripheral lung, have been noted in COPD patients. These elevated values are thought to represent low-grade systemic inflammation. Elevated levels of IL- 6 and TNF- $\alpha$ have been found to be associated with quadriceps wasting in $\mathrm{COPD}^{19}$ and reduced lean body mass (owing to increased activation of the ubiquitin proteosome pathway and apoptosis in the presence of low-grade systemic inflammation). ${ }^{20}$ Elevated levels of IL- 8 have been associated with episodes of COPD exacerbation; however, many recent studies have been unable to show increased levels of proinflammatory cytokines in COPD patients in quadriceps biopsy findings, ${ }^{17,21-23}$ and thus more research is required to determine the contribution of local inflammation to muscle dysfunction. Proximal myopathy is also a well-known consequence of corticosteroid therapy. ${ }^{24}$

The review by Donaldson et $\mathrm{al}^{25}$ summarized the clinical and laboratory findings in the respiratory and peripheral skeletal muscles (the diaphragm and quadriceps in particular) in COPD patients and the current understanding behind the etiological process. Their review observed a $20 \%-30 \%$ reduction of isometric quadriceps strength in COPD patients when compared with healthy controls matched for age and sex, in addition to increased susceptibility to fatigue. The relative loss of fatigue-resistant type I fibers in addition to concurrent structural changes, including reduction in capillary density and capillary muscle fiber contacts, largely explained the reduced quadriceps endurance. ${ }^{8,26} \mathrm{COPD}$ samples in addition also showed reduced aerobic enzyme activity, leading to a greater dependence on glycolysis and early lactate accumulation during exercise, thus limiting activity. ${ }^{27-34}$

Skeletal muscle dysfunction is a known feature of severe or end-stage disease and there is a direct relationship between these two parameters. However, the literature in regard to the relationship between muscle function and severity of COPD is highly unequivocal. Recent data indicate the presence of muscle dysfunction even in the early stages of COPD. Bernard et $\mathrm{al}^{7}$ demonstrated a significant relationship between quadriceps strength and $\mathrm{FEV}_{1}$ percentage of predicted value, with an increase in prevalence of quadriceps weakness with increasing Global Initiative for Chronic Obstructive Lung Disease (GOLD) stage. Seymour et $\mathrm{al}^{35}$ demonstrated quadriceps weakness in approximately one third of COPD patients. They also reported the existence of quadriceps weakness in the absence of severe airflow obstruction or breathlessness, since a significant proportion of patients in GOLD stages 1 and 2 had quadriceps weakness and these values increased in GOLD stage 3 and 4 patients.

A study carried out by Cornell ${ }^{36}$ et al showed similar results. Impaired skeletal muscle endurance was found to be present even in patients with mild-to-moderate airflow obstruction and individuals with relatively normal physical 
activity. Notably, this finding was irrespective of lung function variables, anthropometric data, or quadriceps strength.

Multiple studies exploring the possibility of genetic predisposition to the loss of muscle mass or strength with respect to the long term effects of physical inactivity have been carried out. It was found that the deletion rather than the insertion polymorphic variant of the angiotensin-converting enzyme gene is associated with preserved quadriceps strength in COPD. ${ }^{37}$ This was associated with higher tissue angiotensin-converting enzyme and angiotensin II activity and lower bradykinin levels, which has the potential to affect muscle growth.

An imbalance between anabolic and catabolic hormones in COPD patients may also play a role in muscle dysfunction. Reduced levels of circulating anabolic hormones, such as insulin-like growth factor-1 and testosterone, have been reported in COPD patients. ${ }^{20}$ However, this relationship has been poorly studied and is thus inconclusive. Proximal myopathy is also a well-known consequence of corticosteroid therapy, ${ }^{24}$ and the Leuven group has stressed the importance of steroid myopathy in COPD. ${ }^{38}$

Skeletal muscle dysfunction in COPD can thus be attributed to a myriad of factors. The findings of Kim et al ${ }^{39}$ further acknowledge the role of multiple factors, including the presence of a low-grade systemic inflammatory process, nutritional depletion, corticosteroid medication, chronic inactivity, protein degradation, and changes in vascular density. Skeletal dysfunction in COPD patients thus has a multifactorial etiological basis. Measurement of quadriceps strength in an appropriate and standardized manner in both the clinical and research settings is of utmost importance to obtain valid and reliable results.

The data on prevalence of quadriceps weakness among COPD patients, though prevalent throughout the world, is scarce in India. Therefore, the present study was done with the aim to estimate the prevalence of quadriceps weakness in COPD among patients visiting a tertiary care hospital in South India and to correlate quadriceps muscle weakness, if present, with severity of disease.

\section{Materials and methods}

This cross-sectional study was conducted on an outpatient basis in the Department of Pulmonary Medicine in collaboration with the Department of Physiotherapy. Prior approval from the institutional ethics committee was obtained before commencement of the study. The patients were selected based on the criteria stated in Table $1 .^{40}$
Table I Selection criteria for the study population

\begin{tabular}{ll}
\hline Inclusion criteria & Exclusion criteria \\
\hline Age 45 years or above, & Comorbid chronic lung disease, \\
of either sex & such as bronchiectasis or lung abscess \\
COPD diagnosed by GOLD & Concomitant tuberculosis \\
criteria & Concomitant asthma, as diagnosed \\
Provision of consent and & by GINA guidelines ${ }^{40}$ \\
willingness to participate & Concomitant diabetes \\
& Myopathy of any other kind \\
\hline
\end{tabular}

Abbreviations: COPD, chronic obstructive pulmonary disease; GINA, Global Initiative for Asthma; GOLD, Global Initiative for Chronic Obstructive Lung Disease.

A sample size of 75 was calculated. Eligible patients were recruited into the study. A written informed consent was obtained before doing any study-related activity/procedure. The study power was calculated at $90 \%$. The following formula was used.

$$
\mathrm{n}=\frac{\left(\mathrm{Z}_{\mathrm{a}}+\mathrm{Z}_{\mathrm{b}}\right)^{2}}{\mathrm{C}^{2}}+3
$$

where $Z_{\mathrm{a}}=1.96$ at $95 \%$ confidence limit, $\mathrm{Z}_{\mathrm{b}}=1.28$ at $90 \%$ power, assumes a $50 \%$ correlation $(r=0.5)$.

$$
\mathrm{C}=0.5 \times \ln \frac{(1+r)}{(1-r)}
$$

Height, weight, and age were recorded before commencement of testing. Each subject was required to sit on a high sitting chair; with back supported and feet off the floor. The segmental length of the dominant lower leg was measured from the medial joint line to the medial malleolus using a standard measuring tape. With the knee in 90 degrees flexion, the plate of a push pull hand-held dynamometer (HHD) was placed at $85 \%$ of the segmental length on the anterior surface of the leg, perpendicular to the long axis of the tibia. The subject was then asked to generate a maximal knee extension force by pushing against the dynamometer plate, and to hold the same for a duration of 5 seconds. The maximum force generated was recorded in kilograms. Two more trials were given following the same procedure, with a rest interval of 30 seconds between attempts. The best of three values was documented as the maximal isometric force generated.

The HHD was developed to aid therapists in clinics and to overcome the limitations of manual muscle testing methods. The HHD offers the advantage of being small and portable. These devices measure muscle strength objectively in kilograms, pounds, and newtons. ${ }^{41}$ In a single test, they 
can assess the strength of a patient at only one joint angle, rather than through the patient's entire range of motion. This technique, while providing for clinical quantification of joint strength at a fixed position (isometric), cannot assess dynamic muscle performance. ${ }^{42}$ Isokinetic dynamometers, such as the Biodex, are considered the gold standard for simultaneous strength and angle measurements in evaluation of dynamic muscle performance. They offer the advantage of determining various strength profiles, showing instantaneous torque versus joint angle and a number of properties such as dynamic peak torque, peak torque angle, angle specific torque, power, and energy. ${ }^{43}$ However, the size and cost of these devices make them impractical for routine clinical examinations. Comparison studies between the two instruments, as carried out by Martin et $\mathrm{al}^{44}$ show that the HHD offers a feasible, inexpensive, and portable test of quadriceps muscle strength for use in the elderly. It is found to underestimate the absolute quadriceps strength compared with the Biodex in stronger people, but is a useful tool for ranking muscle strength of older people in epidemiological studies. It is also a valuable tool for rapid and objective assessment of physical function in the clinical setting.

Since there was no published literature available that documented normative values for quadriceps muscle strength in the normal Indian population, the values for quadriceps strength obtained in a study using similar methods ${ }^{45}$ done in a healthy elderly Indian population of North India was used as a reference to categorize our sample and check for the proportion of weakness among them.

The severity of disease was assessed using the GOLD staging system, which classifies people with COPD based on their degree of airflow limitation (obstruction). ${ }^{46}$ The airflow limitation was measured during pulmonary function tests. Severity was established as per the GOLD criteria. Pulmonary function testing was carried out as per American Thoracic Society guidelines. ${ }^{47}$ Descriptive statistics were done using Pearson's correlation coefficient and analysis of variance was used to express the results.

\section{Results}

Of the 75 COPD patients who took part in the study, 59 $(78.6 \%)$ were male and $16(21.4 \%)$ were female. The majority $(58.6 \%)$ of the participants were aged $60-75$ years. Their overall mean age was 67.8 years, with the average age of the female participants ( 70.7 years) being higher than that of the male participants ( 67.0 years; $P=0.150$ ). The overall average height was $1.60 \mathrm{~m}$. In general, the male participants tended to be taller (mean $1.62 \mathrm{~m}$ ) as compared with the female participants (mean $1.50 \mathrm{~m}$ ).

The overall mean body weight and body mass index (BMI) was $57.4 \mathrm{~kg}$ and $22.3 \mathrm{~kg} / \mathrm{m}^{2}$, with males having a higher mean in both categories. As expected, the right limb was dominant in $93.3 \%$ of the participants. The majority (30.7\%) of the participants suffered from severe COPD and were classified as having stage 3 COPD as per the GOLD criteria (Figure 1).

We observed that as the grade of COPD worsened, there was a reduction in mean quadriceps muscle force, and this relationship was found to be significant $(P \leq 0.01)$. Since the $P$-value is $<0.001$, we conclude that there was a significant difference in mean quadriceps muscle force across the various stages of COPD. Based on the Tukey HSD post hoc test, the quadriceps strength in stage 1 COPD patients was significantly different from that in stage 2 COPD, stage 3 COPD, and stage 4 COPD patients (Table 2).

Within our sample, we observed that 69 (92\%) of the 75 participants showed quadriceps muscle weakness. All stage 4 COPD (GOLD classification) patients showed muscle weakness, while only 13 (76.5\%) of 17 stage 1 COPD participants had quadriceps muscle weakness. The prevalence of quadriceps weakness among participants classified as having stage 2 or stage 3 COPD was also very high (95.2\% and $95.7 \%$, respectively, Table 3 ).

We also observed a negative relationship between participant age and production of quadriceps muscle force. The quadriceps force value decreased with increasing age, ie, the force produced by elderly participants was less than that produced by their younger counterparts $(r=-0.675)$. The correlation was found to be statistically significant $(P \leq 0.001$; Figure 2).

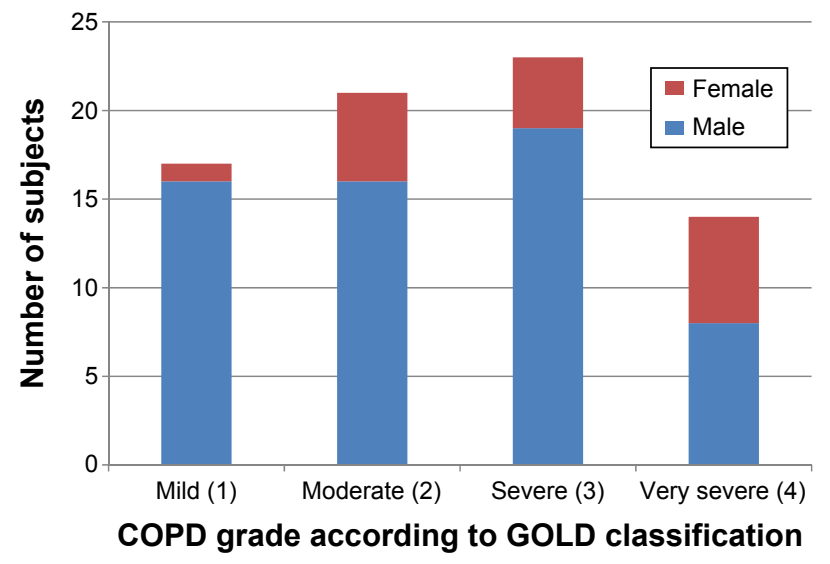

Figure I Distribution of subjects according to COPD grade (GOLD classification). Abbreviations: COPD, chronic obstructive pulmonary disease; GOLD, Global Initiative for Chronic Obstructive Lung Disease. 
Table 2 Relationship between quadriceps muscle force and COPD grade (GOLD classification)

\begin{tabular}{|c|c|c|c|c|c|c|c|c|}
\hline \multirow[t]{2}{*}{ COPD grade } & \multicolumn{4}{|c|}{ Quadriceps muscle force } & \multicolumn{2}{|l|}{ Range } & \multirow[t]{2}{*}{ F-value } & \multirow[t]{2}{*}{$P$-value } \\
\hline & $\mathbf{n}$ & Mean (kg) & SD & SE & Minimum & Maximum & & \\
\hline I & 17 & 22.2941 & 2.91043 & 0.70588 & 17.00 & 27.00 & 38.547 & $<0.001$ \\
\hline 2 & 21 & 17.6667 & $3.2455 I$ & 0.70823 & 13.00 & 24.00 & & \\
\hline 3 & 23 & |3.739| & 3.36043 & 0.70070 & 9.00 & 23.00 & & \\
\hline 4 & 14 & 10.0000 & 4.26073 & 1.13873 & 4.00 & 17.00 & & \\
\hline Total & 75 & 16.0800 & 5.43204 & 0.62724 & 4.00 & 27.00 & & \\
\hline
\end{tabular}

Abbreviations: SD, standard deviation; SE, standard error; COPD, chronic obstructive pulmonary disease; GOLD, Global Initiative for Chronic Obstructive Lung Disease.

Most participants (44 of 75) were in the age group of 61-75 years. Even though the maximum number (eight of $14,18.1 \%$ ) of grade 4 COPD patients were aged $61-75$ years, the highest proportion of grade 4 COPD patients (five of 15 , $33.3 \%$ ) was observed in the age group 76 years and older.

The mean quadriceps muscle force also decreased with increasing age. Table 4 shows the distribution of participants in different stages of COPD according to age.

Within our sample, we observed that muscle weakness was present in the majority of the participants in the three age groups. All participants in the 45-60-year age group showed muscle weakness, while $93.3 \%$ of those aged 76 years or older showed muscle weakness. Muscle weakness was absent in six (8\%) of the 75 participants, of whom five $(6.7 \%)$ were in the age group of 61-75 years (Table 5).

We observed that the mean quadriceps force produced by the participants decreased as the grade of BMI (World Health Organization classification) decreased, but this relationship was found to be statistically insignificant $(P \geq 0.05)$. However, we found a significant positive correlation between BMI value and quadriceps muscle force $(r=0.496)$, implying that participants with higher BMI had higher quadriceps muscle force $(P \leq 0.001$, Figure 3$)$.

\section{Discussion}

The number of COPD patients $(92 \%)$ in our sample with quadriceps muscle weakness was very high when compared

Table 3 Proportion of quadriceps muscle weakness in participants with different stages of COPD (as per GOLD classification)

\begin{tabular}{|c|c|c|c|c|c|c|}
\hline \multirow{3}{*}{$\begin{array}{l}\text { COPD grade } \\
\text { (GOLD } \\
\text { classification) }\end{array}$} & \multicolumn{4}{|c|}{ Quadriceps muscle weakness } & \multicolumn{2}{|c|}{ Total } \\
\hline & \multicolumn{2}{|c|}{ Present } & \multicolumn{2}{|c|}{ Absent } & \multirow[b]{2}{*}{$\mathbf{n}$} & \multirow[b]{2}{*}{$\%$} \\
\hline & $\mathbf{n}$ & $\%$ & $\mathbf{n}$ & $\%$ & & \\
\hline Mild (I) & 13 & 76.5 & 4 & 23.5 & 17 & 100 \\
\hline Moderate (2) & 20 & 95.2 & 1 & 4.8 & 21 & 100 \\
\hline Severe (3) & 22 & 95.7 & I & 4.3 & 23 & 100 \\
\hline Very severe (4) & 14 & 100 & 0 & 0 & 14 & 100 \\
\hline Total & 69 & 92 & 6 & 8 & 75 & 100 \\
\hline
\end{tabular}

Abbreviations: COPD, chronic obstructive pulmonary disease; GOLD, Global Initiative for Chronic Obstructive Lung Disease. with a recent similar study, ${ }^{35}$ which observed that only approximately one third of COPD patients had quadriceps muscle weakness. Our results are consistent with the observation of Cornell et $a l^{36}$ that peripheral muscle weakness is present in COPD patients. Muscle weakness was observed even in those with relatively normal physical activity levels and mild-to-moderate airflow obstruction, as indicated by its presence in high proportions in both stage 1 and stage 2 COPD subjects in our sample. As expected, quadriceps muscle weakness became more profound as the severity of disease increased, since all our stage 4 COPD patients showed quadriceps muscle weakness.

We observed that muscle weakness was present in a very high proportion in the comparatively younger age group of 45-60 years and that there was a high proportion of muscle weakness present in stage 1 COPD patients. This reiterates the findings and observations of recent studies ${ }^{36,48}$ showing that onset of muscle weakness in COPD patients may precede the onset of symptoms. This is also supported by the observation of Watz et $\mathrm{al}^{13}$ that physical activity and steps per day were reduced even in COPD patients with less severe

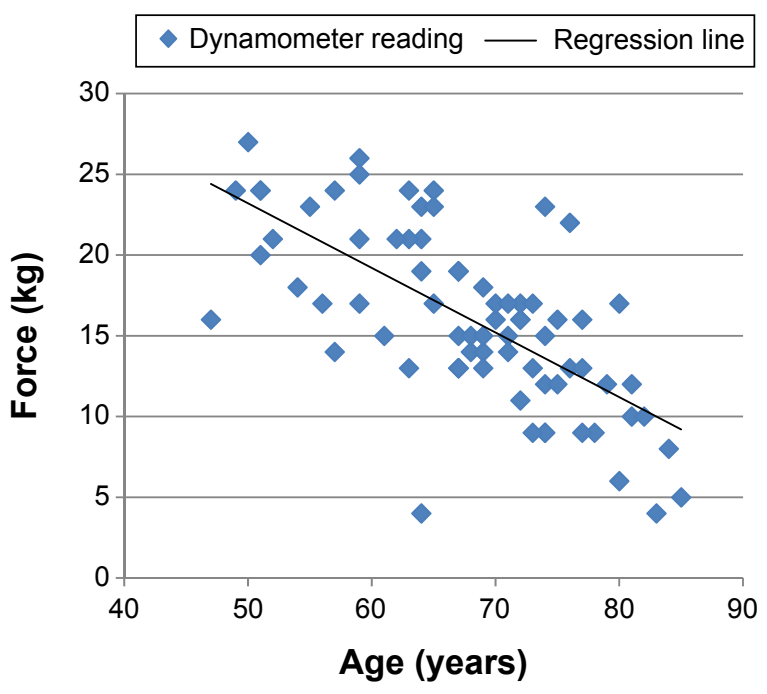

Figure 2 Scatter plot showing the relation between the age and quadriceps muscle force of the participants $(r=-0.675)$. 
Table 4 Distribution of participants in different stages of COPD according to age

\begin{tabular}{|c|c|c|c|c|c|c|c|c|c|c|c|}
\hline \multirow{3}{*}{$\begin{array}{l}\text { Age } \\
\text { (years) }\end{array}$} & \multirow{3}{*}{$\begin{array}{l}\text { Mean quadriceps } \\
\text { muscle force (kg) }\end{array}$} & \multicolumn{8}{|c|}{ COPD grade (GOLD classification) } & \multirow{2}{*}{\multicolumn{2}{|c|}{ Total }} \\
\hline & & \multicolumn{2}{|c|}{ Mild (I) } & \multicolumn{2}{|c|}{ Moderate (2) } & \multicolumn{2}{|c|}{ Severe (3) } & \multicolumn{2}{|c|}{ Very severe (4) } & & \\
\hline & & $\bar{n}$ & $\%$ & $\bar{n}$ & $\%$ & $\bar{n}$ & $\%$ & $\bar{n}$ & $\%$ & $\bar{n}$ & $\%$ \\
\hline $45-60$ & 21.3 & 8 & 50 & 7 & 43 & 0 & 0 & $\mathrm{I}$ & 7 & 16 & 100 \\
\hline $61-75$ & 15.9 & 8 & 18.2 & 12 & 27.3 & 16 & 36.4 & 8 & 18.1 & 44 & 100 \\
\hline$\geq 76$ & II.I & I & 6.7 & 2 & 13.3 & 7 & 46.7 & 5 & 33.3 & 15 & 100 \\
\hline Total & 16.1 & 17 & 22.7 & 21 & 28 & 23 & 30.7 & 14 & 18.6 & 75 & 100 \\
\hline
\end{tabular}

Abbreviations: COPD, chronic obstructive pulmonary disease; GOLD, Global Initiative for Chronic Obstructive Lung Disease.

disease. This could be one of the major factors contributing to COPD patients adapting a sedentary lifestyle early in the disease and limiting their physical activity to lower than the recommended international guidelines for physical health maintenance, as mentioned by Bossenbroek et al. ${ }^{12}$

The physical characteristics of our study sample are comparable with the national data as documented by the Indian Council of Medical Research. ${ }^{49}$ Even though the average weight and height for both men and women were comparatively lower than the national average, the BMI was higher. Loss of body cell mass is a common and serious problem for patients with COPD, being more common in severe end-stage disease..$^{48}$ This usually results in a reduction of body mass and BMI in COPD patients. The absence of such an observation within our sample could be a result of our study sample being limited to COPD patients visiting the hospital on an outpatient basis. The reduction in body mass is more profound in severe end-stage disease, and such patients are more likely to be admitted to tertiary care hospitals, so the opportunity to include these patients in our sample was limited. Another confounding factor in this regard could be the socioeconomic and demographic characteristics of our study sample. The positive correlation between BMI and quadriceps muscle force seen in our study integrates the finding of increased prevalence of muscle weakness and loss of body cell mass in more severe cases of COPD.

Recent data from India ${ }^{50}$ suggest that severity of disease may affect the extent to which skeletal muscle function

Table 5 Proportion of quadriceps muscle weakness according to age group

\begin{tabular}{|c|c|c|c|c|c|c|}
\hline \multirow{3}{*}{$\begin{array}{l}\text { Age group } \\
\text { (years) }\end{array}$} & \multicolumn{4}{|c|}{ Quadriceps muscle weakness } & \multicolumn{2}{|c|}{ Total } \\
\hline & \multicolumn{2}{|c|}{ Present } & \multicolumn{2}{|c|}{ Absent } & & \\
\hline & $\mathbf{n}$ & $\%$ & $\mathbf{n}$ & $\%$ & $\mathbf{n}$ & $\%$ \\
\hline $45-60$ & 16 & 100 & 0 & 0 & 16 & 100 \\
\hline $61-75$ & 39 & 88.6 & 5 & 11.4 & 44 & 100 \\
\hline$\geq 76$ & 14 & 93.3 & I & 6.7 & 15 & 100 \\
\hline Total & 69 & 92 & 6 & 8 & 75 & 100 \\
\hline
\end{tabular}

is compromised. Shah et al reported a significant positive correlation between muscle strength in the upper limb and percentage predicted $\mathrm{FEV}_{1}$, which is consistent with our observations.

The major limitation of our study was the absence of published literature documenting normative values for quadriceps muscle strength in the normal Indian population. The values for quadriceps strength obtained in a study using similar methods in a healthy elderly North Indian population including different age groups was used as a reference to categorize and check for the proportion of weakness within our sample. ${ }^{45}$ This may have led to a discrepancy in our final results. Further, we did not include healthy, matched case-controls in our study, as has been the recent trend..$^{35,36,50}$

Another limitation of our study was its sample size. The results obtained from such a small sample cannot be appropriately applied to the general Indian population. Women were notably under-represented in our sample. Further, the

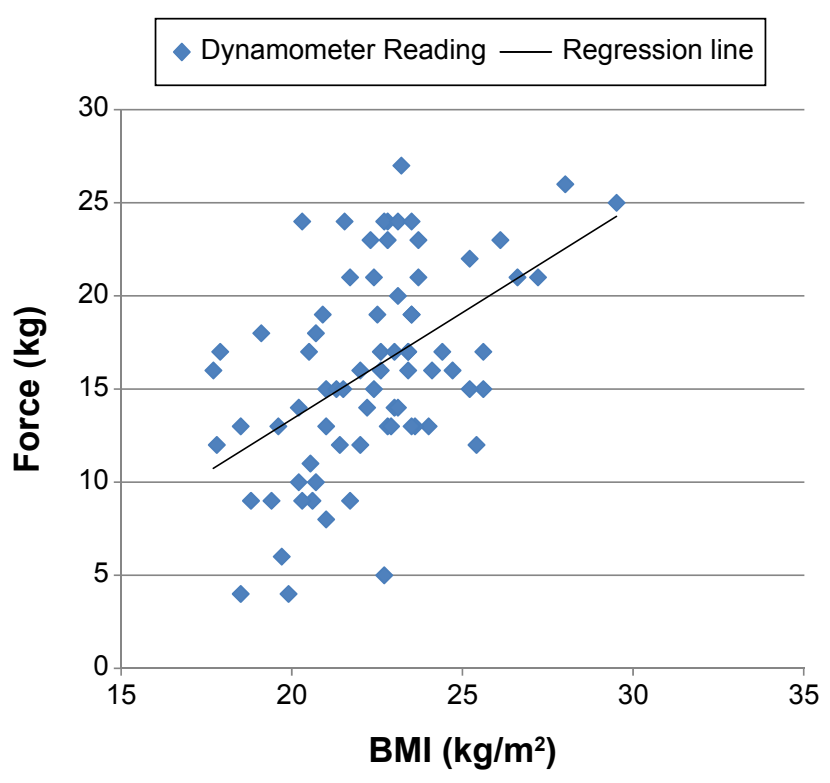

Figure 3 Scatter Plot showing the relation between body mass index (BMI) and the quadriceps muscle force of the participants $(r=0.496)$. 
majority of women in our sample had more severe disease (stage 3 or stage 4 COPD), unlike our male subjects, the majority of whom had milder disease (stage 1 or stage 2 COPD). This uneven sex distribution among the various COPD severity groups could be a source of bias given that less muscle strength can be expected in females than in males. This could also be a reflection of the sex inequality that is prevalent in Indian society, which may be leading to inequitable distribution of health care resources between males and females in India. ${ }^{51}$

Clearly there are additional factors that may determine quadriceps strength and skeletal muscle dysfunction. Personal habits and lifestyle, occupation, socioeconomic status, nutritional status, and the presence of comorbid conditions, can all act as confounding factors when determining quadriceps muscle strength and need to be considered during analysis. The age range selected limits the study to mostly post-menopausal women, and whether the same results can be extended to pre-menopausal women needs to be established. Cardiovascular comorbidity is also common in COPD patients and may have an influence on the final result which was not taken into consideration in the study.

\section{Conclusion}

A very high proportion of COPD patients (92\%) within our sample were found to have quadriceps muscle weakness. Quadriceps muscle weakness was also present in a significantly high proportion among patients with mild disease and in the younger age groups, indicating that the onset of muscle weakness in COPD patients may precede the onset of symptoms, resulting in these patients adopting a sedentary lifestyle early in the disease. Quadriceps weakness becomes all the more important in our culture, wherein most people use "Indian"-style toilets and have a preference for sitting down on the floor. Therefore, quadriceps muscle weakness affects the ability to perform activities of daily living, so has an adverse effect on quality of life as well as mental health. This could pose a major public health challenge. We also observed that as the grade of COPD worsened, there was a reduction in mean quadriceps muscle force, ie, quadriceps muscle weakness was more profound as the severity of disease increased. Further research in different population groups is needed to determine how widely our present observations can be generalized.

\section{Acknowledgments}

The authors are grateful to the Indian Council of Medical Research, New Delhi, India, who approved this project under the Short-Term Student Scholarship 2014 scheme. Thanks are also extended to Drs Prasanna Mithra and Vaman Kulkarni (Department of Community Medicine, Kasturba Medical College, Mangalore), who helped with the statistical analysis.

\section{Disclosure}

We declare that we have no financial and personal relationships with other people or organizations that could inappropriately influence our work; there is no professional or other personal interest of any nature or kind in any product, service, and/or company that could be construed as influencing the position presented in or the review of the manuscript.

\section{References}

1. Agustí AG. Systemic effects of chronic obstructive pulmonary disease. Proc Am Thorac Soc. 2005;2:367-370.

2. Gosselink R, Trooster T, Decramer M. Peripheral muscle contributes to exercise limitation in COPD. Am J Respir Crit Care Med. 1996;153: 976-980.

3. Simpson K, Killian K, McCartney N, Stubbing DG, Jones NL. Randomised controlled trial of weightlifting exercise in patients with chronic airflow limitation. Thorax. 1992;47:70-75.

4. Decramer M, Goselink R, Trooster T, Verschueren M, Evers G. Muscle weakness is related to utilization of health care resources in COPD patients. Eur Respir J. 1997;10:417-423.

5. Swallow EB, Reyes D, Hopkinsons NS, et al. Quadriceps strength predicts mortality in patients with moderate to severe chronic obstructive pulmonary disease. Thorax. 2007;62:115-120.

6. Killian KJ, Leblanc P, Martin DH, Summers E, Jones NL, Campbell EJ. Exercise capacity and ventilatory, circulatory, and symptom limitation in patients with chronic airflow limitation. Am Rev Respir Dis. 1992;146: 935-940.

7. Bernard S, LeBlanc P, Whittom F, et al. Peripheral muscle weakness in patients with chronic obstructive pulmonary disease. Am J Respir Crit Care Med. 1998;158:629-634.

8. Man WD, Soliman M, Nikoletou D, et al. Non-volitional assessment of skeletal muscle strength in patients with chronic obstructive pulmonary disease. Thorax. 2003;58:665-669.

9. Polkey MI, Kyroussis D, Hamnegard C-H, Mills GH, Green M, Moxham J. Diaphragm strength in chronic obstructive pulmonary disease. Am J Respir Crit Care Med. 1996;154:1310-1317.

10. Maltais F, LeBlanc P, Simard C, et al. Skeletal muscle adaptation to endurance training in patients with chronic obstructive pulmonary disease. Am J Respir Crit Care Med. 1996;154:44.

11. Neder JA, Sword D, Ward SA, Mackay E, Cochrane LM, Clark CJ. Home based neuromuscular electrical stimulation as a new rehabilitative strategy for severely disabled patients with chronic obstructive pulmonary disease (COPD). Thorax. 2002;57: 333-337.

12. Bossenbroek L, de Greef MH, Wempe JB, Krijnen WP, Ten Hacken NH. Daily physical activity in patients with chronic obstructive pulmonary disease: a systematic review. COPD. 2011;8:306-319.

13. Watz H, Waschki B, Meyer T, Magnussen H. Physical activity in patients with COPD. Eur Respir J. 2009;33:262-272.

14. Polkey MI, Moxham J. Attacking the disease spiral in chronic obstructive pulmonary disease. Clin Med. 2006;6:190-196.

15. Decramer M, Rennard S, Troosters T, et al. COPD as a lung disease with systemic consequences - clinical impact, mechanisms, and potential for early intervention. COPD. 2008;5:235-256. 
16. Creutzberg EC, Schols AM, Weling-Scheepers CA, et al. Characterization of nonresponse to high caloric oral nutritional therapy in depleted patients with chronic obstructive pulmonary disease. Am J Respir Crit Care Med. 2000;161:745-752.

17. Eid AA, Ionescu AA, Nixon LS, et al. Inflammatory response and body composition in chronic obstructive pulmonary disease. Am J Respir Crit Care Med. 2001;164(8 Pt 1):1414-1418.

18. Spruit MA, Gosselink R, Troosters T, et al. Muscle force during an acute exacerbation in hospitalised COPD patients and its relationship with CXCL8 and IGF-1. Thorax. 2003;58:752-756.

19. Pitta F, Troosters T, Spruit MA, Probst VS, Decramer M, Gosselink R. Characteristics of physical activities in daily life in chronic obstructive pulmonary disease. Am J Respir Crit Care Med. 2005;171: 972-977.

20. Debigaré R, Marquis K, Côté $\mathrm{CH}$, et al. Catabolic/anabolic balance and muscle wasting in patients with COPD. Chest. 2003;124: 83-89.

21. Barreiro E, Schols AM, Polkey MI, et al. ENIGMA in COPD project. Cytokine profile in quadriceps muscles of patients with severe COPD. Thorax. 2008;63:100-107.

22. Petersen AM, Penkowa M, Iversen M, et al. Elevated levels of IL-18 in plasma and skeletal muscle in chronic obstructive pulmonary disease. Lung. 2007;185:161-171.

23. Crul T, Spruit MA, Gayan-Ramirez G, et al. Markers of inflammation and disuse in vastus lateralis of chronic obstructive pulmonary disease patients. Eur J Clin Invest. 2007;37:897-904.

24. Bowyer S, LaMothe M, Hollister J. Steroid myopathy: incidence and detection in a population with asthma. J Allergy Clin Immunol. 1985;76: 234-242.

25. Donaldson AV, Maddocks M, Martolini D, Polkey MI, Man WD. Muscle function in COPD: a complex interplay. Int J Chron Obstruct Pulmon Dis. 2012;7:523-535.

26. Man WD, Hopkinson NS, Harraf F, Nikoletou D, Polkey MI, Moxham J. Abdominal muscle and quadriceps strength in chronic obstructive pulmonary disease. Thorax. 2005;60:718-722.

27. Gosker HR, Zeegers MP, Wouters EF, Schols AM. Muscle fiber type shifting in the vastus lateralis of patients with COPD is associated with disease severity: a systemic review and meta-analysis. Thorax. 2007; 62:944-949.

28. Whitton F, Jobin J, Simard PM, et al. Histochemical and morphological characteristics of the vastus lateralis muscle in patients with chronic obstructive pulmonary disease. Med Sci Sports Exerc. 1998;30: $1467-1474$.

29. Jobin J, Maltais F, Doyon JF, et al. Chronic obstructive pulmonary disease: capillarity and fiber type characteristics of skeletal muscle. J Cardiopulm Rehabil. 1998;18:432-437.

30. Maltais F, Simard AA, Simard C, et al. Oxidative capacity of the skeletal muscle and lactic acid kinetics during exercise in normal subjects and in patients with COPD. Am J Respir Crit Care Med. 1996;153: 288-293.

31. Jakobsson P, Jorfeldt L, Henriksson J. Metabolic enzyme activity in the quadriceps femoris muscle in patients with severe chronic obstructive pulmonary disease. Am J Respir Crit Care Med. 1995;151(2 Pt 1): 374-377.

32. Kutsuzawa T, Shioya S, Kurita D, Haida M, Ohta Y, Yamabayashi H. Muscle energy metabolism and nutritional status in patients with chronic obstructive pulmonary disease. A 31P magnetic resonance study. Am J Respir Crit Care Med. 1995;152:647-652.

33. Maltais F, Jobin J, Sullivan MJ, et al. Metabolic and hemodynamic responses of lower limb during exercise in patients with COPD. J Appl Physiol (1985). 1998;84:1573-1580.
34. Levine S, Nguyen T, Kaiser LR, et al. Human diaphragm remodeling associated with chronic obstructive pulmonary disease: clinical implications. Am J Respir Crit Care Med. 2003;168:706-713.

35. Seymour JM, Spruit MA, Hopkinson NS, et al. The prevalence of quadriceps weakness in COPD and the relationship with disease severity. Eur Respir J. 2010;36:81-88.

36. Cornell C, Orozco-Levi M, Méndez R, Ramírez-Sarmiento A, Gáldiz JB, Gea J. Relevance of assessing quadriceps endurance in patients with COPD. Eur Respir J. 2004;24:129-136.

37. Hopkinson NS, Nickol AH, Payne J, et al. Angiotensin converting enzyme genotype and strength in chronic obstructive pulmonary disease. Am J Respir Crit Care Med. 2004;170:395-399.

38. Decramer M, de Bock V, Dom R. Functional and histologic picture of steroid-induced myopathy in chronic obstructive pulmonary disease. Am J Respir Crit Care Med. 1996;153:1958-1964.

39. Kim HC, Mofarrahi M, Hussein S. Skeletal muscle dysfunction in patients with chronic obstructive pulmonary disease. Int $J$ Chron Obstruct Pulmon Dis. 2008;3:637-658.

40. From the Global Strategy for Asthma Management and Prevention, Global Initiative for Asthma (GINA) 2015. Available from: http://www.ginasthma.org/. Accessed June 13, 2015.

41. Le-Ngoc L, Janssen J. Validity and reliability of a hand-held dynamometer for dynamic muscle strength assessment. In: Kim CT, editor. Rehabilitation Medicine. InTech, 2012. Available from: http://www.intechopen.com/books/rehabilitation-medicine/validityand-reliability-of-a-hand-held-dynamometer-for-dynamic-musclestrength-assessment. Accessed June 13, 2015.

42. Andrews AW, Thomas MW, Bohannon RW. Normative values for isometric muscle force measurements obtained with hand-held dynamometer. Phys Ther. 1996;76:248-259.

43. Kannus P. Isokinetic evaluation of muscular performance: implications for muscle testing and rehabilitation. Int J Sports Med. 1994;15 Suppl 1: S11-18.

44. Martin HJ, Yule V, Syddall HE, Dennison EM, Cooper C, Aihie Sayer A. Is hand-held dynamometry useful for the measurement of quadriceps strength in older people? A comparison with the gold standard Biodex dynamometry. Gerontology. 2006;52:154-159.

45. Aggarwal SR, Kumar D. Lower extremity muscle strength and balance performance in Indian community dwelling elderly men aged 50 years and above. Available from: http://www.indmedica.com/journals.php? journalid $=10 \&$ issueid $=85 \&$ articleid $=1154 \&$ action $=$ article. Accessed July 20, 2015.

46. Global Strategy for the Diagnosis, Management and Prevention of COPD, Global Initiative for Chronic Obstructive Lung Disease (GOLD) 2015. Available from: http://www.goldcopd.org/. Accessed June 13, 2015.

47. Wanger J, Clausen JL, Coates A, et al. Standardisation of the measurement of lung volumes. Eur Respir J. 2005;26:511-522.

48. Shrikrishna D, Patel M, Tanner R, et al. Quadriceps wasting and physical inactivity in patients with COPD. Eur Respir J. 2012;40:1115-1122.

49. Indian Council of Medical Research. Nutrient requirements and recommended dietary allowances for Indians - a report of the expert group of the Indian Council of Medical Research 2009. Available from: http:// icmr.nic.in/final/RDA-2010.pdf. Accessed October 9, 2014.

50. Shah S, Nahar P, Vaidya S. Upper limb muscle strength and endurance in chronic obstructive pulmonary disease. Indian J Med Res. 2013; 138:492-496.

51. Pal P, Ghosh J. Inequality in India: a survey of recent trends. DESA working paper no 45. 2007. Available from: http://www.un.org/esa/ desa/papers/2007/wp45_2007.pdf. Accessed October 9, 2014. 
International Journal of COPD

\section{Publish your work in this journal}

The International Journal of COPD is an international, peer-reviewed journal of therapeutics and pharmacology focusing on concise rapid reporting of clinical studies and reviews in COPD. Special focus is given to the pathophysiological processes underlying the disease, intervention programs, patient focused education, and self management protocols. manuscript management system is completely online and includes a very quick and fair peer-review system, which is all easy to use. Visit $\mathrm{http}: / / \mathrm{www}$.dovepress.com/testimonials.php to read real quotes from published authors.

Submit your manuscript here: http://www.dovepress.com/international-journal-of-chronic-obstructive-pulmonary-disease-journal 